\title{
Determination of optimal placement of UPFC to minimize power losses in the system using Gravitational search algorithm
}

\author{
Bairu VijayKumar, \\ EEED, KITSWarangal, India. \\ Email:bairuvijaykumar@gmail.com
}

\begin{abstract}
In this paper, power system loss minimization using UPFC placed at optimal location given by Gravitational Search Algorithm is proposed. Here, the Gravitational Search Algorithm (GSA) optimizes the location of the UPFC, while the generator outage occurs. The generator outage affects the power flow constraints like power loss, voltage magnitude, real and reactive power flows. By connecting UPFC at the optimum location power flows are improved, which causes reduction in power loss. The proposed method is implemented in the MATLAB/simulink platform. The performance of proposed method is evaluated by comparing power loss under different conditions i.e. normal condition, generator outage condition and after connecting UPFC at optimal location which is given $\mathrm{ABC}$ algorithm and GSA. The comparison results demonstrate the superiority of the proposed approach and confirm its potential to find optimal location of UPFC.
\end{abstract}

Keywords: UPFC, GSA, Power loss, Power flows

\section{INTRODUCTION}

The amount of electric power that can be transmitted through a transmission network is restricted by stability constraints [1]. Around the world, Electric power systems are forced to work to at their full capacities due to the environmental and economic constraints to erect novel generating plants and transmission lines [2] [3]. For controlling the power transmission system, Flexible Alternating Current Transmission System (FACTS) is a stationary tool that is used [4] [5]. FACTS is identified as "a power electronic based system and other stationary tool that offer control of one or more AC transmission system parameters to improve controllability and amplify power transfer capability" [6]. The different kinds of FACTS tools accessible for this purpose comprises Static Var Compensator (SVC), Thyristor controlled series Capacitor (TCSC), Static Synchronous series compensator (SSSC), Static Synchronous Compensator (STATCOM), Unified Power Flow Controller (UPFC) and Interlink Power Flow Controller (IPFC) [7].

UPFC is one of the FACTS tools among them that can manage the power flow in transmission line by inserting active and reactive voltage component in series with the broadcasting line [8]. Unified power flow controller (UPFC) [9] can be used for power flow control, loop-flow control, load sharing among parallel corridors, enhancement of transient stability, mitigation of system oscillations and voltage (reactive power) regulation. Novel opportunities for controlling power and improving the utilizable capacity of surviving transmission lines are released up by the appearance of FACTS devices [10]. An optimal location of UPFC tool permits to control its power flows for a meshed network, and as a result to raise the system load ability [11]. Dissimilar kinds of optimization algorithm have been applied to find out optimal location of UPFC, such as genetic algorithms, simulated annealing, tabu search and etc [12].

In this paper, heuristic technique based minimization of power loss of the power system using UPFC is proposed. Here, the Gravitational Search Algorithm (GSA) optimizes the location of the UPFC, while the generator outage occurs. The generator outage affects the power flow constraints like power loss, voltage magnitude, real and reactive power flows. By connecting UPFC at the optimum location power flows are improved, which causes reduction in power loss. The proposed method is implemented in the MATLAB/Simulink platform. The performance of proposed method is evaluated by comparing power loss under different conditions i.e. normal condition, generator outage condition and after connecting UPFC at optimal location which is given $\mathrm{ABC}$ algorithm and GSA. The comparison results demonstrate the superiority of the proposed approach and confirm its potential to find optimal location of UPFC. 


\section{International Journal of Research in Advent Technology, Vol.7, No.5, May 2019 E-ISSN: 2321-9637 Available online at www.ijrat.org}

\section{RECENT RESEARCH WORK: A BRIEF REVIEW}

Numbers of related works are available in literature, which are based on enhancing the power transfer capability of power system. A few of them are reviewed here.

Ghamgeen Izat Rashed et al. [13] presented a Differential Evolutionary (DE) algorithm for finding the optimal location and the best parameter setting of Unified Power Flow Controller (UPFC) for minimizing the active and reactive power losses in the power system.

A novel strategy for optimal placement of PWM based Series Compensator (PWMSC) in huge power systems have been brought in by A. Safari et al. [14]. The proposed approach is based on the Selective Modal Analysis (SMA) and dynamics index to damp out the inter-area oscillation modes. $\mathrm{m}$. The effectiveness of the proposed algorithm is demonstrated on the 16-machine five-area power system for various network conditions.

Using Fuzzy logic and Real Coded Genetic Algorithm, an approach for appointment and sizing of shunt FACTS controller has been suggested by A.R. Phadke et al. [15]. A blurry presentation index based on distance to encumber node bifurcation, voltage profile and capacity of shunt FACTS controller is suggested. In order to find the most efficient location, the suggested method can be applied and optimal size of the shunt FACTS tools. The suggested strategy has been used on IEEE 14bus and IEEE 57-bus test systems.

Sanjeev Kumar et al. [16]. have proposed an efficient and reliable evolutionary based approach to solve the optimal power flow (OPF) problems. The integration of Fuzzy Systems with Genetic Algorithm (GA) and Particle Swarm Optimization (PSO) algorithm for optimal setting of OPF problem control variables. Their approach has been tested on the modified IEEE 30-bus test system with objective function that reflects fuel cost minimization with different linear and non-linear constraints. The results have been compared with the results those reported in the literature.

B.Vijay kumar et al have attempted the problem of optimal location of UPFC to improve power system voltage stability using Artificial Bee Colony algorithm [17]. They were carried out simulation studies on IEEE 14 bus system.

B.Vijay kumar et al have attempted the problem of optimal location of UPFC to improve power system voltage stability using Gravitational search algorithm [18]. They were carried out simulation studies on IEEE 14 bus system.
B.Vijay kumar et al have attempted the problem of optimal location of UPFC to minimize power loss of power system using Artificial Bee Colony algorithm [19]. They were carried out simulation studies on IEEE 30 bus system.

During the last decade, continuous and fast improvement of power electronics technology has made flexible AC transmission systems (FACTS) a promising concept for power system applications. With the application of FACTS technology, power flow along transmission lines can be more flexibly controlled. Among a variety of FACTS controllers, UPFC is one of the more interesting and potentially the most versatile. it can provide simultaneous and independent control of important power system parameters: line active power flow, line reactive power flow, impedance; and voltage. [20]. Practically, the optimal location of UPFC tends not by randomly, and the matching methodical exploration is not frequently adequate. Several researches have effort to solve the optimal location of UPFCs with respect to different purposes and methods. For determining the optimal location, the operating condition of UPFC must be pre-assigned which can be taken as simultaneously. Some of the optimization algorithms are introduced to determine the location of UPFC such as genetic algorithm, particle swarm optimization, differential evaluation and etc. but these methods are inferior in terms searching ability to give optimal location hence a new heuristic approach is needed to find location of UPFC. The proposed method is briefly described in the following section.

\section{UPFC STRUCTURE AND POWER FLOW MODEL}

The UPFC consists of two identical inverters, i.e., parallel inverter and series inverter, which are connected in parallel and series to power systems through corresponding power transformers. The UPFC is connected between the buses $i$ and $j$ through the series and parallel power transformers [21], the structure of the UPFC is described in the Fig. 1. The parallel inverter can operates either voltage controller or constant reactive power source. It injects constant positive or negative reactive power Qi at $i^{\text {th }}$ bus and regulates the voltage of the bus. The series inverter independently controls the active power $\mathrm{Pj}$ and reactive power $\mathrm{Qj}$ of the $\mathrm{j}^{\text {th }}$ bus at associated settings, which distinguishes the UPFC from the STATCOM and SSSC. Also the series inverter is used to regulate the difference between the $i^{\text {th }}$ bus voltage $V_{i}$ and $j^{\text {th }}$ bus voltage $V_{j}$. The UPFC installation structure in 


\section{International Journal of Research in Advent Technology, Vol.7, No.5, May 2019 \\ E-ISSN: 2321-9637 \\ Available online at www.ijrat.org}

power system and the equivalent circuit is given in the following Fig. 1 and 2.

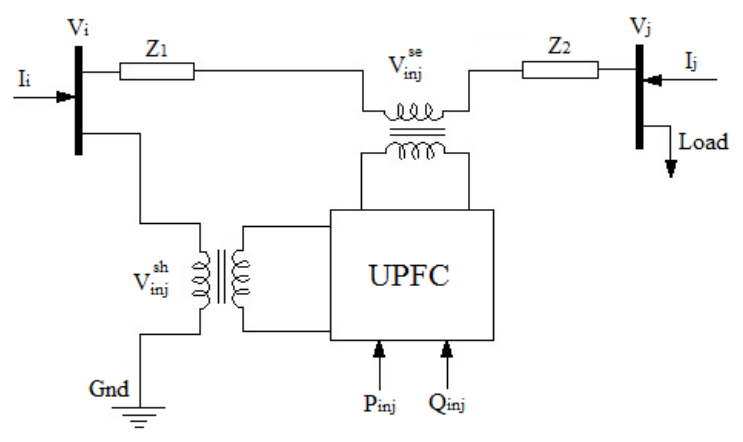

Figure.1. UPFC installation in power system

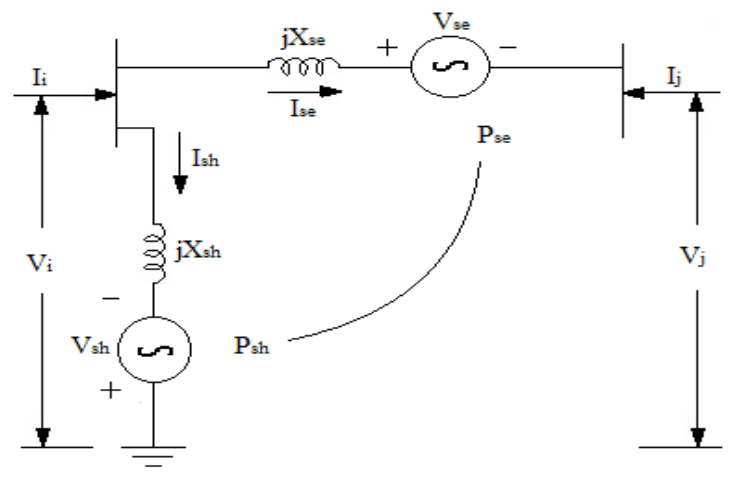

Figure.2. Equivalent model of UPFC

From the above equivalent circuit model, the power injection at each node can be derived using the power flow studies. By using the load flow solution, the real and reactive power at the bus $i$ and $j$ is calculated. The important of the power injection representation is that the symmetric characteristics of admittance matrix will not be destroyed [22]. The real and reactive power injection at each bus is described [23] in the following.

Power flows from $i$ to $j$ :

$$
\begin{aligned}
P_{i j}(t)= & \left(V_{i}{ }^{2(t)}+V_{k l}{ }^{2(t)}\right) G_{i j}{ }^{(t)}+2 V_{i}^{(t)} V_{k l}{ }^{(t)} G_{i j}{ }^{(t)} \cos \left(\alpha_{k l}-\phi_{j}\right) \\
& -V_{j}^{(t)} V_{k l}{ }^{(t)}\left[G_{i j}{ }^{(t)} \cos \left(\alpha_{k l}-\phi_{j}\right)+b_{i j}{ }^{(t)}\left(\sin \alpha_{k l}-\phi_{j}\right)\right] \\
& -V_{i}^{(t)} V_{j}^{(t)}\left(G_{i j}{ }^{(t)} \cos \phi_{i j}+b_{i j}{ }^{(t)} \sin \phi_{i j}\right)
\end{aligned}
$$

$$
\begin{aligned}
Q_{i j}(t)= & -V_{i}^{(t)} I^{(t)}-V_{i}^{2(t)}\left(b_{i j}{ }^{(t)}+B / 2\right) \\
& -V_{i}^{(t)} V_{k l}{ }^{(t)}\left[G_{i j}^{(t)} \sin \left(\alpha_{k l}-\phi_{i}\right)+b_{i j}^{(t)}\left(\cos \alpha_{k l}-\phi_{i}\right)\right] \\
& -V_{i}^{(t)} V_{j}^{(t)}\left(G_{i j}{ }^{(t)} \sin \phi_{i j}-b_{i j}{ }^{(t)} \cos \phi_{i j}\right)
\end{aligned}
$$

Where, $G_{i j}+j b_{i j}=\frac{1}{R_{i j}+j X_{i j}}, V_{i}$ and $V_{j}$ are the voltage of the buses $i$ and $j$ and $V_{k l}$ is the voltage of the compensating device,

The problem formulation of minimization of power loss using optimal placement of UPFC is briefly explained in the following section A.

\subsection{Problem formulation}

The Power system loss minimization is a nonlinear optimization problem. To achieve this, control variables should be maintained at the secure limits. The control variables in terms of a certain objective function are various equality and inequality constraints. The required objective function is mathematically described in the following equations (3), (4) and (5).

$$
\begin{gathered}
\text { Minimize } F(t, u) \\
\text { Subject to } g(t, u)=0 \\
h(t, u) \leq 0
\end{gathered}
$$

Where, $F(t, u)$ is the objective function of the power system stability, which minimizes the power system loss and voltage deviation under generator outage conditions. The outage of generator(s) causes increase in the power loss and increase in voltage deviations at buses, which affects the stability of the system. Here one objective function is considered that is minimization of system loss. Then, $g(t, u)$ are the equality constraints and $h(t, u)$ are the inequality constraints. The equality and inequality constraints are explained in the following section (i).

\subsection{Objective function}

Here objective is to minimize active power loss. The active power loss in the transmission network can be defined as follows: [24]

$P_{\text {loss }}=\sum_{k \in N_{E}} g_{k}\left(V_{i}^{2}+V_{j}^{2}-2 V_{i} V_{j} \cos \theta_{i j}\right)$

Where $k=(i, j) ; N_{E}$ is the set of numbers net work branches, $g_{k}$ is the conductance of branch $k$. $\theta_{i j}$ is the voltage angle difference between bus $i$ and $\mathrm{j}$.

\subsection{Equality constraints}

In this section explains the power system equality constraints. Here, the power system generators need 


\section{International Journal of Research in Advent Technology, Vol.7, No.5, May 2019 \\ E-ISSN: 2321-9637 \\ Available online at www.ijrat.org}

to ensure the customers total demand and the transmission loss. It is also known as power balance condition of the power system. The power system stability condition is affected by the generators outage, which increase the power loss of the system and affects the dynamic stability environment. The required power balance condition can be described in the following equation (7).

$$
\sum_{i=1}^{N_{G}} P_{G i}=P_{D}+\sum_{j=1}^{N_{l}}\left(P_{L j}\right)
$$

Where, $P_{G i}$ is the power generated in the $i^{\text {th }}$ bus, $P_{D}$ is the demand, $P_{L j}$ is the real power loss of the $j^{\text {th }}$ line.

The inequality constraints are explained in the following section.

\subsection{Inequality Constraints}

This section describes the inequality constraints of the power system [24], i.e., voltage, real and reactive power and transformer tap positions. These constraints should be maintained at the stability limit. The power stability mainly considers the voltage stability of every node., hence bus voltage limits are mainly considered in the problem. For the stable operation of power system, bus voltage should be $V_{i}^{\text {min }} \leq V_{i} \leq V_{i}^{\text {max }}$. Normally voltage limit of every node may be 0.95 to $1.05 \mathrm{pu}$. Other Inequality constraints are given below

$\mathrm{V}_{\mathrm{i}}^{\min } \leq \mathrm{V}_{\mathrm{i}} \leq \mathrm{V}_{\mathrm{i}}^{\text {max }}$ Bus voltage limits

$\mathrm{T}_{\mathrm{i}}^{\min } \leq \mathrm{T}_{\mathrm{i}} \leq \mathrm{T}_{\mathrm{i}}^{\text {max }}$ Tap position limits

$\mathrm{Q}^{\text {min }} \leq \mathrm{Q} \leq \mathrm{Q}^{\text {max }}$ Reactive power $\mathrm{P}$

$\mathrm{P}_{\mathrm{i}}^{\min } \leq \mathrm{P}_{\mathrm{i}} \leq \mathrm{P}_{\mathrm{i}}^{\text {max }}$ active power generation

These constraints are satisfied under normal stable condition. During the generator outage condition, the power flow constraints are affected, which makes increase in power loss. In these conditions, the power system loss can be minimized by connecting an UPFC at optimal location. This can be achieved using proposed GSA algorithm

\subsection{Gravitational Search Algorithm (GSA)}

Gravitational Search Algorithm (GSA) is one of the latest Trajectory based Metaheuristic Algorithm, which was first introduced by Rashedi, Nezamabadi and Saied [25, 26] based on the metaphor of gravitational interaction between masses. GSA is inspired by the Newton theory that says: each particle attracts every other particle with a "gravitational force". The gravitational force between two bodies is directly proportional to the product of their masses and inversely proportional to the square of their distance.

In GSA, each mass (agent) has four specifications: its position, its inertial mass, its active gravitational mass, and its passive gravitational mass. Where inertial mass is measure of an object resistance to changing its state of motion when force is applied, active gravitational mass is a measure of the strength of gravitational field due to a particular object, and passive gravitational mass is measure of the strength of an object's interaction with the gravitational field. The position of the mass corresponds to a solution of the problem, and its gravitational and inertial masses are determined using a fitness function.

\subsection{Determination of Optimum location of UPFC using $G S A$}

This section describes about the GSA based optimum location determination. Initially the IEEE standard benchmark system normal power flow is analyzed using the N-R load flow analysis. Then the generator outage is introduced in the bus system, so the system becomes instability. Here, the GSA technique is used to find the most affected location to place the UPFC, i.e., maximum power loss bus. The maximum power loss bus is the most suitable location to connect UPFC.

The steps to find the optimum location are given in the following section.

\section{Steps to find the optimum location}

Step 1: In the first step, the input agents are randomly generated at $\mathrm{N}$ dimensions. Here, the bus voltage and the line losses are selected as the agents.

Step 2: Apply load flow solution and then, evaluate the fitness values of the random number of agents.

Step 3: In the high mass, agents are selected as the best solutions and the corresponding load flow is analyzed.

Step 4: The best solutions are separated into two groups, the first groups have the minimum best solutions and another group has maximum best solutions.

Step 5: For each best solution groups, the agent's positions and velocity is modified.

Step 6: Run load flow analysis and evaluate the new agents. Select the best agent from each group. 


\section{International Journal of Research in Advent Technology, Vol.7, No.5, May 2019 \\ E-ISSN: 2321-9637 \\ Available online at www.ijrat.org}

Step 7: Find the voltage, real and reactive power flow and power loss.

Step 8: Check the termination criterion. If it is satisfied terminate or else go to step 9 .

Step 9: Generate the new agents to generate new solutions. Go to Step 2.

Once the process is finished, the GSA is ready to give the optimal location of the UPFC.

Once the termination criterion is attained, the system is ready to give the optimum location of the UPFC. The selected location is utilized and the load flows are analyzed. The proposed method is tested in the MATLAB platform and the numerical results are analyzed with various techniques, which are briefly described in the next section 4 .

\section{RESULTS AND DISCUSSIONS}

The proposed method is implemented in MATLAB/simulink) platform. Here the IEEE 30 bus system is used to validate the proposed method. The numerical results of the proposed method is presented and discussed in this section. The effectiveness of the proposed method is analyzed by comparing results under various conditions. The proposed method is applied in the IEEE 30 bus system and discussed in the following section 4.1 .

\subsection{Validation of IEEE 30 Bus Systems}

The proposed method is tested on the IEEE 30 bus system and the corresponding numerical results are analyzed in this section. The IEEE 30 bus system consists of 6 generator bus, 21 load bus and 42 transmission lines. The IEEE 30 bus system structure is illustrated in Figure 3. Initially, the system base case load flow analysis is done by the standard Newton-Raphson (N-R) algorithm. Here, the IEEE 30 bus system standard data is used. Afterwards, the generator outages (single and double) are introduced and the corresponding power flows are analyzed. Due to the generator outages power flows will get disturb and the system loses will increase. Increased Power loss can be minimized by connecting UPFC placed at optimal location, which can be determined by the proposed GSA algorithm.

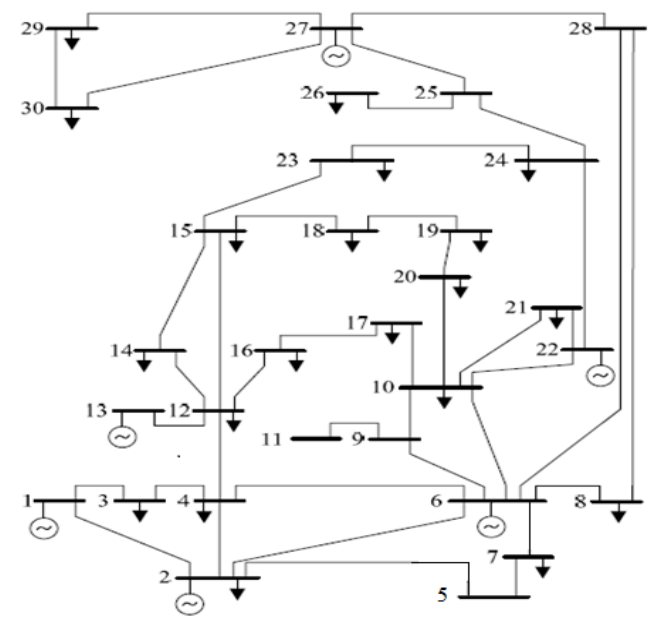

Figure 3. Structure of the IEEE 30 bus system

\subsubsection{Single generator outage condition}

In this case at a time one generator is given outage and corresponding stability is analyzed

Table 1 shows power flows during normal condition, generator outage condition and after connecting UPFC placed at optimal location for different single generator outage conditions. Here, it is observed that power flows are improved after connecting UPFC whose location is determined by GSA algorithm.

Table 2 shows power loss at normal condition, generator outage condition and after connecting UPFC at optimal location for different single generator outage conditions. Here, it is observed that by connecting UPFC, power loss of the system is reduced. Here, it can be observed that power loss is increased to $12.768 \mathrm{MW}$ during single generator outage and it is reduced to $8.715 \mathrm{MW}$ after connecting UPFC whose location is given by proposed GSA algorithm

Table 1. Power flow analysis at single generator outage condition with GSA

\begin{tabular}{|c|c|c|c|c|c|c|c|c|}
\hline \multirow{2}{*}{$\begin{array}{c}\text { Generator } \\
\text { bus no. }\end{array}$} & \multicolumn{2}{|c|}{ Best location } & \multicolumn{2}{|c|}{$\begin{array}{c}\text { During normal } \\
\text { condition }\end{array}$} & \multicolumn{2}{c|}{$\begin{array}{c}\text { During generator } \\
\text { outage condition }\end{array}$} & $\begin{array}{c}\text { After placing UPFC at } \\
\text { optimal location given } \\
\text { by GSA }\end{array}$ \\
\cline { 2 - 9 } & $\begin{array}{c}\text { From } \\
\text { bus }\end{array}$ & $\begin{array}{c}\text { To } \\
\text { bus }\end{array}$ & P(MW) & Q(MVAR) & P(MW) & Q(MVAR) & P(MW) & Q(MVAR) \\
\hline 2 & 12 & 15 & 19.676 & 7.795 & 19.799 & 7.754 & 19.721 & 2.378 \\
\hline 6 & 5 & 7 & 23.745 & 13.826 & 24.770 & 14.245 & 23.454 & 14.123 \\
\hline
\end{tabular}


International Journal of Research in Advent Technology, Vol.7, No.5, May 2019

E-ISSN: 2321-9637

Available online at www.ijrat.org

\begin{tabular}{|l|l|l|l|l|l|l|l|l|}
\hline 13 & 12 & 15 & 19.674 & 7.797 & 19.799 & 7.755 & 19.686 & 7.789 \\
\hline 22 & 10 & 22 & 4.048 & 6.616 & 4.044 & 6.581 & 3.957 & 6.406 \\
\hline 27 & 22 & 24 & 7.911 & 3.146 & 9.714 & 1.940 & 8.492 & 3.209 \\
\hline
\end{tabular}

Table 2. Power loss analysis at single generator condition with GSA

\begin{tabular}{|c|c|c|c|c|c|}
\hline \multirow{2}{*}{$\begin{array}{c}\text { Generator } \\
\text { bus no. }\end{array}$} & \multicolumn{2}{|c|}{ Best location } & \multicolumn{3}{|c|}{ Power loss in MW } \\
\cline { 2 - 3 } & From bus & To bus & $\begin{array}{c}\text { During normal } \\
\text { condition }\end{array}$ & $\begin{array}{c}\text { During generator } \\
\text { outage condition }\end{array}$ & $\begin{array}{c}\text { After placing UPFC at } \\
\text { optimal location given by } \\
\text { GSA }\end{array}$ \\
\hline 2 & 12 & 15 & \multirow{2}{*}{10.809} & 12.768 & 8.715 \\
\hline 6 & 5 & 7 & 15 & 12.549 & 8.082 \\
\hline 13 & 12 & 12 & & 12.791 & 8.541 \\
\hline 22 & 10 & 22 & & 11.879 & 8.059 \\
\hline 27 & 22 & 24 & & 11.907 & 8.513 \\
\hline
\end{tabular}

Table 3. Power flow analysis at double generator outage condition with GSA

\begin{tabular}{|c|c|c|c|c|c|c|c|c|}
\hline \multirow{2}{*}{$\begin{array}{c}\text { Generator } \\
\text { bus no. }\end{array}$} & \multicolumn{2}{|c|}{$\begin{array}{c}\text { Best location } \\
\text { bus }\end{array}$} & $\begin{array}{c}\text { To } \\
\text { bus }\end{array}$ & \multicolumn{2}{|c|}{$\begin{array}{c}\text { During normal } \\
\text { condition }\end{array}$} & \multicolumn{2}{c|}{$\begin{array}{c}\text { During generator } \\
\text { outage condition }\end{array}$} & \multicolumn{2}{|c|}{$\begin{array}{c}\text { After placing UPFC at optimal } \\
\text { location given by GSA }\end{array}$} \\
\cline { 2 - 10 } & & & P(MW) & Q(MVAR) & P(MW) & Q(MVAR) & P(MW) & Q(MVAR) \\
\hline 2 and 6 & 10 & 22 & 1.047 & 6.617 & 4.044 & 6.581 & 0.331 & 6.495 \\
\hline 2 and 13 & 5 & 7 & 23.744 & 13.825 & 24.763 & 14.248 & 24.071 & 13.971 \\
\hline 6 and 13 & 15 & 23 & 5.893 & 3.546 & 2.003 & 4.598 & 5.421 & 3.731 \\
\hline 22 and 27 & 12 & 15 & 19.675 & 7.796 & 19.797 & 7.755 & 19.725 & 7.908 \\
\hline 13 and 27 & 2 & 5 & 72.803 & 2.549 & 77.585 & 2.087 & 75.245 & 2.496 \\
\hline
\end{tabular}

Table 4. Power loss analysis at double generator outage condition with GSA

\begin{tabular}{|c|c|c|c|c|c|}
\hline \multirow{2}{*}{$\begin{array}{c}\text { Generator } \\
\text { bus no. }\end{array}$} & \multicolumn{2}{|c|}{ Best location } & \multicolumn{3}{|c|}{ Power loss in MW } \\
\hline & $\begin{array}{c}\text { From } \\
\text { bus }\end{array}$ & $\begin{array}{c}\text { To } \\
\text { bus }\end{array}$ & $\begin{array}{l}\text { During normal } \\
\text { condition }\end{array}$ & $\begin{array}{l}\text { During generator } \\
\text { outage condition }\end{array}$ & $\begin{array}{c}\text { After placing UPFC at optimal } \\
\text { location given by GSA }\end{array}$ \\
\hline 2 and 6 & 10 & 22 & \multirow{5}{*}{10.809} & 14.731 & 8.531 \\
\hline 2 and 13 & 5 & 7 & & 15.017 & 8.798 \\
\hline 6 and 13 & 15 & 23 & & 14.833 & 8.729 \\
\hline 22 and 27 & 12 & 15 & & 13.051 & 8.279 \\
\hline 13 and 27 & 2 & 5 & & 14.005 & 8.129 \\
\hline
\end{tabular}




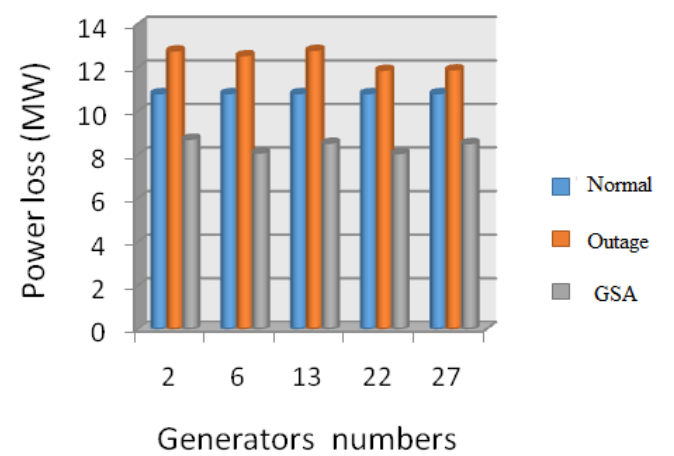

Figure 4. Power loss comparison at single generator outage

The power loss comparison at single generator outage shown in the Figure 4. It shows the performance of the proposed method, because the power loss has been reduced compared to the normal condition and the outage condition.

\subsubsection{Double generators outage condition}

In this case at a time two generators are given outages and corresponding stability is analyzed. Table 3 shows power flows for normal condition, double generator outage condition and after connecting UPFC whose optimal location is determined by GSA algorithm. Here, it is observed that power flows are improved after connecting the UPFC.

Table 4 shows power loss at normal condition, double generator outage condition and after connecting UPFC at optimal location which is determined by GSA algorithm. Here, it is observed that by connecting UPFC, power loss of the system is reduced. Here, it can be observed that power loss is increased to $14.731 \mathrm{MW}$ during double generator outage and it is reduced to $8.531 \mathrm{MW}$ after connecting UPFC whose location is given by proposed GSA algorithm.

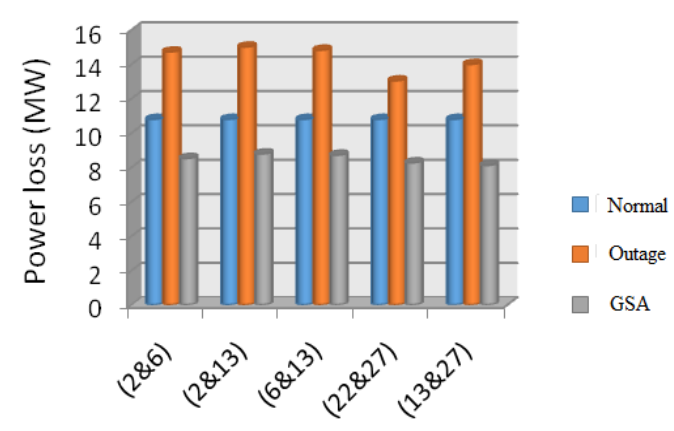

Generators numbers

Figure 5. Power loss comparison at double generator outage

Table 2 and Table 4 show effectiveness of proposed method of finding optimal placement of UPFC to reduce power loss in the system. The power loss comparison at double generator outage is shown in the Figure 5. It can be observed that the power loss has been reduced as compared to the normal condition and the outage condition. It shows the performance of the proposed method.

From the above tabular forms and graphs it is clear that the proposed method is effectively selects the optimum location of the UPFC as compared to the other optimization techniques and reduces power loss in the power system

\section{CONCLUSION}

This paper proposed a heuristic technique based power loss minimization of the power system using optimal placement of UPFC. Here, optimal location was determined by GSA technique.. The proposed heuristic method is tested on IEEE 30 bus system at different generator outages. In these conditions, the power flows and the power loss are analyzed. The obtained numerical results were compared and the performances were discussed. From the comparison results it can be concluded that the proposed heuristic technique is the well effective technique to determine optimal location of UPFC in the power system

\section{REFERENCES}

[1] P. Ramasubramanian, G. Uma Prasana, and K. Sumathi, "Optimal Location of FACTS Devices by Evolutionary Programming Based OPF in Deregulated Power Systems", British Journal of Mathematics \& Computer Science, Vol.2, No.1, pp.21-30, 2012

[2] Rakhmad Syafutra Lubis, Sasongko Pramono Hadi, and Tumiran, "Selection of Suitable 


\section{International Journal of Research in Advent Technology, Vol.7, No.5, May 2019 E-ISSN: 2321-9637 Available online at www.ijrat.org}

Location of the FACTS Devices for Optimal Power Flow", International Journal of Electrical \& Computer Sciences, Vol.12, No.3, pp.38-49, 2012

[3] S.Durairaj, and B.Fox, "Optimal Placement of Facts Devices", International Conference on Energy \& Environment, 2008

[4] Rahul J. Shimpi, Rajendra P. Desale, Kunal S. Patil, Jaswantsing L. Rajput and Shailesh B. Chavan, "Flexible AC Transmission Systems", International Journal of Computer Applications, Vol.1, No.15, pp.54-57, 2010

[5] P. K. Dash, S. R. Samantaray, and Ganapati Panda, "Outage Classification and Section Identification of an Advanced SeriesCompensated Transmission Line Using Support Vector Machine", IEEE Transaction on Power Delivery, Vol.22, No.1, pp.67-73, January 2007

[6] H O Bansal, H P Agrawal, S Tiwana, A R Singal and L Shrivastava, "Optimal Location of FACT Devices to Control Reactive Power", International Journal of Engineering Science and Technology, Vol.2, No.6, pp.1556-1560, 2010

[7] Xuan Wei, Joe H. Chow, Behruz Fardanesh and Abdel-Aty Edris, "A Common Modeling Framework of Voltage-Sourced Converters for Load Flow, Sensitivity, and Dispatch Analysis", IEEE Transactions On Power Systems, Vol.19, No.2, pp.934-941, May 2004

[8] D. Murali, and M. Rajaram, "Active and Reactive Power Flow Control using FACTS Devices", International Journal of Computer Applications, Vol.9, No.8, pp.45-50, 2010

[9] L. Gyugyi, C.D. Schauder, S.L. Williams, T.R. Rietman, D.R. Torgerson, A. Edris, "The Unified Power Flow Controller: A New Approach to Power Transmission Control", IEEE Trans., Vol. PWRD-10, No. 2, pp. 1085-1097, April 1995.

[10] Jigar S.Sarda, Vibha N.Parmar, Dhaval G.Patel, and Lalit K.Patel, "Genetic Algorithm Approach for Optimal location of FACTS devices to improve system loadability and minimization of losses", International Journal of Advanced Research in Electrical, Electronics and Instrumentation Engineering, Vol.1, No.3, pp.114-125, 2012

[11] Gerbex, S., Cherkaoui, R., and Germond, A.J., "Optimal location of FACTS devices to enhance power system security", IEEE Bologna Power Tech Conference Proceedings, 2003

[12] Mori, H., and Goto, Y., "A parallel tabu search based method for determining optimal allocation of FACTS in power systems", International Conference on Power System Technology, 2000

[13] Ghamgeen Izat Rashed, Yuanzhang Sun, Khalid A. Rashed, and H. I. Shaheen, "Optimal Location of Unified Power Flow Controller by Differential Evolution Algorithm Considering Transmission Loss Reduction", IEEE POWECON 2012, pp1-6.

[14] A.Safari, H.A. Shayanfar and A. Kazemi, "Optimal location of PWM based series compensator in a power system", International Journal of Electrical Power \& Energy Systems, Vol.51, pp.127-133, October 2013.

[15] A.R. Phadke, and Manoj Fozdar, K.R. Niazi, "A new multi-objective fuzzy-GA formulation for optimal placement and sizing of shunt FACTS controller", International Journal of Electrical Power \& Energy Systems, Vol.40, No.1, pp.46-53, September 2012

[16] A. Safari, H.A. Shayanfar and A. Kazemi, "Optimal location of PWM based series compensator in a power system", International Journal of Electrical Power \& Energy Systems, Vol.51, pp.127-133, October 2013.

[17] B.Vijay kumar "Optimal Location of UPFC to Improve Power System Voltage Stability Using Artificial Bee Colony Algorithm", American Journal of Electrical Power and Energy Systems 2019; 8(2): 42-49.

[18] B.Vijay kumar "Improvement of power system voltage stability by using UPFC placed at optimal location given by gravitational search algorithm" global journal for research analysis, vol.8, issue 5, may 2019.

[19] B.Vijay kumar, "Power System loss minimization by using UPFC placed at optimal location given by Artificial Bee Colony Algorithm" International journal of research in advent technology,

[20] Gehengouda " Power Flow Control using UPFC Device", International Journal Of Control, Automation And Systems Vol.3 No.2 April 2014.

[21] A. Rajabi-Ghahnavieh, M. Fotuhi-Firuzabad, M. Shahidehpour and R. Feuillet, "UPFC for Enhancing Power System Reliability", IEEE Transactions on Power Delivery, Vol.25, No.4, pp.2881-2890, October 2010.

[22] Wanliang Fang, and H.W. Ngan, "A robust load flow technique for use in power systems with unified power flow controllers", Electric Power 
Systems Research, Vol.53, No.3, pp.181-186, 2000.

[23] Arup Ratan Bhowmik and Champa Nandi, "Implementation of Unified Power Flow Controller (UPFC) for Power Quality Improvement in IEEE 14-Bus System", Int. J. Comp. Tech. Appl, Vol.2, No.6, pp.1889-1896, 2011.

[24] Chaohua Dai, Weirong Chen, Yunfang Zhu, and Xuexia Zhang, "Reactive power dispatch considering voltage stability with seeker optimization algorithm", Electric Power Systems Research, Vol.79, No.10, pp.1462-1471, October 2009.

[25] Esmat Rashedi, Hossein Nezamabadi-pour, Saeid Saryazdi "GSA: A Gravitational Search Algorithm", Information Sciences 179 (2009) 2232-2248.

[26] Esmat Rashedi , Hossien Nezamabadi-pour, Saeid Saryazdi, Malihe M. Farsangi "Allocation of Static Var Compensator Using

Gravitational Search Algorithm" First Joint Congress on Fuzzy and Intelligent Systems
Ferdowsi University of Mashhad, Iran 29-31 Aug 2007.

\section{Author's Biography}

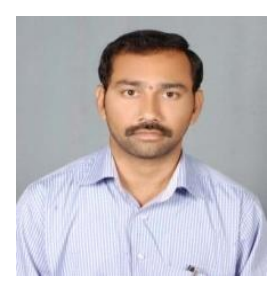

Dr. B. Vijay Kumar was born in Warangal, India, in April 1978. He received the B. Tech degree in Electrical \& Electronics Engineering, M. Tech degree in Power Systems Engineering and Ph.D in Electrical Engineering from National Institute of Technology, Warangal, India, in 2002, 2008 and 2015 respectively. He is currently working as Asst. professor in EEED of Kakatiya institute of Technology \& Science, Warangal, India. He published 15 research papers in various journal including SCI indexed journals. He also authored three books on power system. His Current research interest includes Enhancement of Power System Stability using FACTS devices and AI techniques. 